\title{
THE FRICTION EFFECT IN THE SERIAL SONIC CIRCUIT
}

\author{
BAL, C. \& BAL, N.
}

Abstract: In this paper we present the practical application of the thermal effect in the theory of sonicity. The sonic actions permit the best combination of facilities offered by the processing of electrical signals (reduces energy) with sonic actions of high power and efficiency and gives the possibility of eliminating the biggest parts of a classical hydraulically system (hydraulic reservoir, valve of regulating the debit). The result of this action which combine the opportunities offered by the processing the signals of low energy and the compact sonic actions with high efficiency are a reduced volume and a very economical solution. In the paper we present the effect of the friction used the sonic pressure and the sonic flow in one sonic installation. This installation is formed by one serial cylinders and one frictions resistance. The effects produced in this case are the caloric effects by the increase of the temperature in the friction resistance.

Key words: sonic serial circuit, sonic pressure, sonic flow, friction resistance, temperature
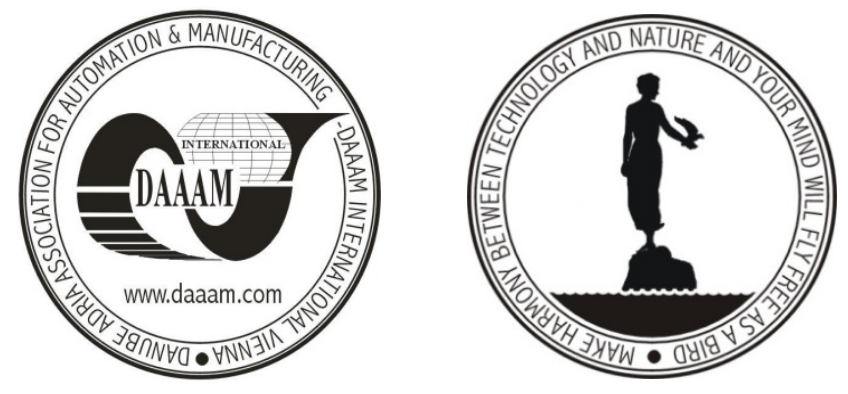

Authors' data: Univ.Prof. Dipl.-Ing. Dr. Bal, C[armen]*; Univ.Prof. Dipl.-Ing. Dr. Bal, N[icolaie ${ }^{* *}$, *Technical University of Cluj Napoca, Constantin Daicoviciu 15, 400020, Cluj Napoca, Romania, ** Technical University of Cluj Napoca, B-dul Muncii 102-103, 400020, Cluj Napoca, Romania, carmen.bal@dppd.utcluj.ro, nicubal@yahoo.com

This Publication has to be referred as: Bal, C[armen] \& Bal, N[icolaie] (2009). The Friction Effect in the Serial Sonic Circuit, Chapter 66 in DAAAM International Scientific Book 2009, pp. 685-692, B. Katalinic (Ed.), Published by DAAAM International, ISBN 978-3-901509-69-8, ISSN 1726-9687, Vienna, Austria DOI: $10.2507 /$ daaam.scibook.2009.66 